\title{
IMPLEMENTASI METODE LOAD BALANCING DALAM MENDUKUNG SISTEM KLUSTER SERVER
}

\author{
Sampurna Dadi Riskiono \\ Fakultas Teknik dan Ilmu Komputer, Universitas Teknokrat Indonesia \\ Jl. Z. A. Pagar Alam No.9 -11, Labuhan Ratu, Kedaton, Kota Bandar Lampung, Lampung \\ ${ }^{1}$ sampurna.go@teknokrat.ac.id
}

\begin{abstract}
ABSTRAK
Dewasa ini, pertumbuhan internet semakin pesat, hal tersebut akan memicu peningkatan jumlah pengguna yang tergabung didalamnya. Kondisi tersebut berimbas pada kebutuhan akan server penyedia layanan yang akan terus meningkat yang di akibatkan oleh jumlah client yang terus bertambah dari waktu ke waktu. Beberapa situs bahkan telah menerima ratusan ribu koneksi dari client secara simultan. Ketika jumlah pengguna yang mengakses layanan server meningkat dan server tidak dapat mengatasinya, tentu ini akan menjadi masalah yang mengakibatkan layanan server terhenti. Penyebabnya adalah adanya beban berlebih yang diterima oleh suatu server tunggal. Oleh karena itu diperlukan penelitian untuk merancang bagaimana membangun sistem server yang dapat menangani banyaknya permintaan layanan yang masuk agar beban dari server dapat diatasi. Hal ini bertujuan untuk meningkatkan layanan yang dapat diberikan oleh server penyedia kepada penggunanya. Salah satu yang dapat diupayakan untuk mengatasi permasalahan tersebut adalah penggunaan banyak server. Sehingga diperlukan metode yang mampu mendistribusikan beban ke masingmasing server. Dimana dalam pengujian yang dilakukan, skalabilitas sistem menjadi meningkat. Ini dibuktikan ketika sistem dengan load balancing diberiakan 300 koneksi, memiliki nilai response time 4,99 ms serta throughput 148,2 KB/s dan ini lebih baik jika dibandingkan dengan sistem tanpa load balancing yang memiliki nilai response time 1145,4ms dan throughput 121,4 KB/s. Sehingga dengan implementasi load balancing, maka kinerja layanan dari sistem kluste server dapat terus ditingkatkan.
\end{abstract}

Kata kunci: Metode load balancing dan sistem kluster server

\section{PENDAHULUAN}

Dalam upaya meningkatkan kinerja ketika adanya akses layanan yang sangat banyak, maka penggunaan sistem kluster server dapat menjadi sebuah solusi untuk mengatasi hal tersebut. Sehingga dengan menerapkan kluster server, maka keandalan dan ketersediaan aplikasi dapat terus ditingkatkan (Lukitasari dan Oklilas, 2010) (Kopper, K., 2005). Server load balancer dapat bertugas untuk mendistribusikan beban kerja ke banyak server, dengan mempertimbangkan kapasitas dari setiap server yang ada. Hal ini dapat mengurangi terjadinya kegagalan server yang terjadi pada server tunggal (W. Tarreau, 2006). Setiap permintaan yang masuk kemudian didistribusikan ke masing-masing server sehingga beban yang ada menjadi terdistribusi. Sistem terdistribusi menyediakan berbagai sumberdaya, sebagai salah satu keuntungan utamanya adalah dapat menyediakan kinerja yang lebih baik serta keandalan dari pada sistem tradisional yang lain dalam kondisi yang sama (Kopparapu, C., 2002). Penggunaan banyak server untuk sistem terdistribusi membutuhkan metode untuk mengatur pembagian beban secara adil atau merata pada masing-masing server. Banyak penelitian telah dilakukan terkait penerapan metode load balancing untuk mengatur pembagian beban kerja pada server dengan tujuan untuk meningkatkan kinerja sistem. Penerapan load balancing dalam web server sangat penting dan dapat merupakan sebuah solusi yang tepat dan efektif untuk menangani beban server yang sibuk serta diharapkan dapat meningkatkan skalabilitas pada sistem terdistribusi (Rabu, J.A., Purwadi, J., dan Raharjo, 2012). Permasalahan lain yang muncul ketika sistem telah didistribusikan di masing-masing server adalah bila adanya kesalahan atau kegagalan pada hardware atau software dari sistem tersebut. Web server harus bebas dari kegagalan baik akibat dari hardware ataupun software. Beberapa penelitian telah dilakukan untuk menangani kegagalan tersebut yaitu dengan menerapkan toleransi terhadap kegagalan. Toleransi kegagalan dapat diterapkan untuk mendeteksi dan mentoleransi kerusakan secara real-time pada sistem terdistribusi (K. Bumi, and T. Anduonohu, 2016).

\section{LANDASAN TEORI}

\section{A. Metode Load Balancing}

Load balancing adalah sebuah metodologi jaringan komputer untuk mendistribusikan beban kerja di beberapa komputer atau kluster komputer untuk mencapai pemamfaatan optimal sumber daya, memaksimalkan throughput, meminimalkan waktu respon, dan menghindari kelebihan beban. Kluster server terdiri dari beberapa perangkat komputer yang saling terhubung dan bekerjasama sehingga mereka dapat dilihat sebagai satu sistem dalam banyak aspek, dan kluster komputer biasanya digunakan untuk meningkatkan kinerja dan 
ketersediaan atas satu komputer (Rabu, J.A., Purwadi, J., dan Raharjo, 2012). Load balancers dapat melakukan berbagai fungsi seperti load balancing, traffic engineering, dan switching cerdas trafik. Load balancers dapat melakukan pemeriksaan kesehatan pada server, aplikasi, dan konten untuk meningkatkan ketersediaan layanan dan pengelolaanya (E. Mit, N. H. Borhan, and M. A. Khairuddin, 2012). Dalam penerapan load balancer ada berbagai metode atau algoritma yang dapat digunakan untuk mendistribusikan beban kepada setiap server didalam sekumpulan server. Alat pengujian load balancing dalam penelitian ini menggunakan program aplikasi httperf untuk mendapatkan data throughput dan waktu respon.

\section{B. Waktu Respon}

Waktu respon adalah total waktu yang dibutuhkan dari saat permintaan atau permintaan akan menunggu untuk menerima jawaban. Dalam penelitian ini pengukuran waktu respon dimaksudkan untuk menentukan seberapa cepat aplikasi web merespon permintaan dari pengguna (K. Bumi, and T. Anduonohu, 2016).

\section{Throughput}

Throughput merupakan parameter kinerja yang memberikan gambaran mengenai besarnya data yang dapat dikirim dalam satu satuan waktu tertentu. Semakin banyak data yang dapat dikirim dalam satu satuan waktu tertentu maka semakin baik kinerja suatu sistem. Throughput pada penelitian ini digunakan untuk melihat bandwidth actual atau jumlah bit yang ditransmisikan dalam satuan waktu byte per second (bps) baik sebelum load balancing maupun setelah penerapan load balancing (K. Bumi, and T. Anduonohu, 2016).

\section{METODE PENELITIAN}

Metode penelitian yang digunakan didalam penelitian ini adalah eksperimental. Untuk mendukung kelancaran penelitian yang dilakukan, hal pertama yang dikerjakan adalah mencari dan mengumpulkan berbagai literatur yang mengarah kepada berbagai metode load balancing dan aspek lain yang mendukung. Perancangan load balancing menggunakan berbagai metode yang selanjutnya akan diterapkan beberapa algoritma penjadwal. Pengujian server load balancing dilakukan dengan memberikan sejumlah permintaan dengan nilai yang sudah ditentukan. Pengolahan data dan analisis data sesuai dengan skenario yang akan diberikan terhadap server load balancing dalam mendistribusikan beban yang diterimanya. Dalam melakukan penelitian ini secara lebih detail metode yang akan dilakukan ditunjukkan seperti pada Gambar 1.

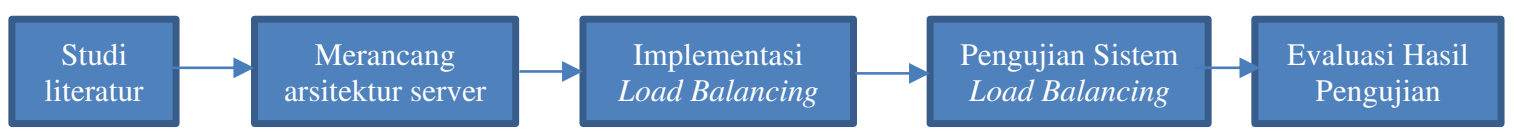

Gambar 1. Tahapan metode penelitian

\section{A. Skenario Pengujian Load Balancing}

Skenario pengujian ini dilakukan terhadap sistem load balancing yang telah dibangun. Hal tersebut dilakukan untuk menguji kemampuan dari sistem load balancing, yaitu dengan cara melakukan permintaan atau koneksi dengan jumlah permintaan yang berbeda, antara 100, 200, 300, 400 dan 500 koneksi pada waktu tertentu untuk mendapatkan nilai parameter dari response time dan throughput.

\section{B. Arsitektur Sistem Server Load Balancing}

Arsitektur dari sistem server load balancing ini memiliki tiga bagian seperti diperlihatkan pada Gambar 2 yang mana terdiri dari server load balancer, server application 1, server application 2 serta server database.

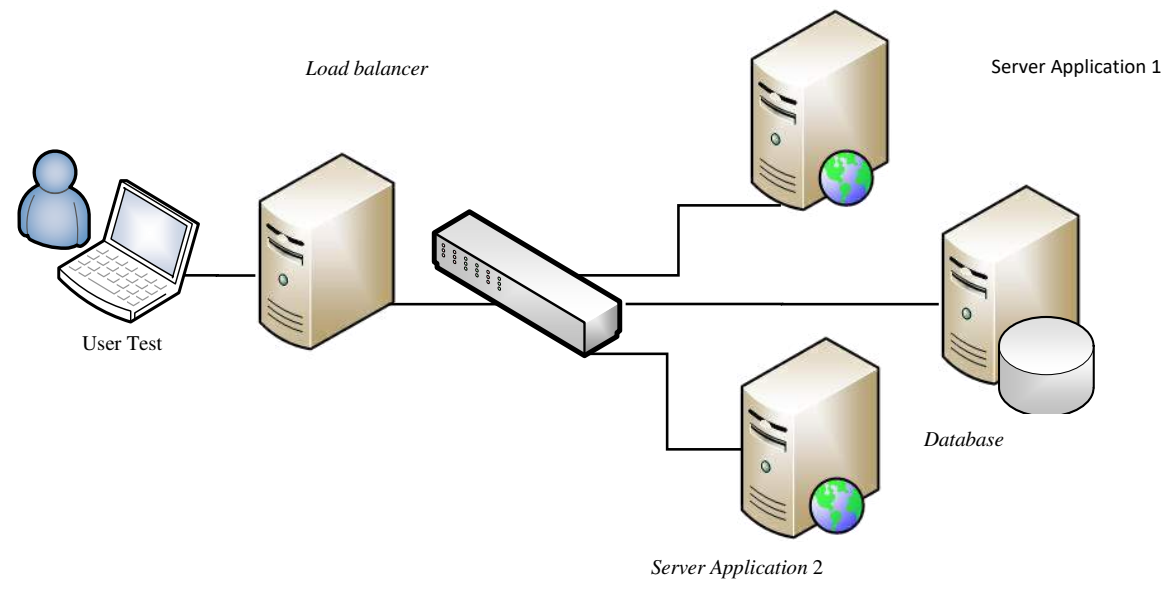


Pada bagian yang pertama terdiri dari server load balancer yang berperan dalam mendistribusikan beban koneksi yang masuk ke masing-masing server aplikasi. Server load balancing ini dikonfigurasi dengan alamat IP 192.168.100.107. Kemudian pada bagian kedua adalah server aplikasi yang terdiri dari 2 server. Server aplikasi 1 dikonfigurasi dengan alamat IP 192.168.100.108 sedangkan untuk server aplikasi 2 dikonfigurasi dengan alamat IP 192.168.100.109. Kedua server ini didalamnya menjalankan program aplikasi web. Sedangkan untuk bagian yang ketiga adalah storage atau penyimpanan database yang terdiri dari sebuah server database. Server database ini dikonfigurasi dengan alamat IP 192.168.100.110. sistem ini di implementasikan dan diujikan dalam jaringan LAN. Berikut ini spesifikasi server yang digunakan dalam penelitian, antara lain:

a) Satu unit server load balancing yang memiliki spesifikasi Processor Intel Pentium Core ${ }^{\text {TM }} 2$ Duo @ 2,93GHz, RAM 2 GB, Hard Disk 250 GB, dengan OS Linux Ubuntu Server.

b) Dua unit server application yang memiliki spesifikasi Processor Intel Pentium Core 2 Duo @ 2,93GHz, RAM 2 GB, Hard Disk 250 GB, dengan OS Linux Ubuntu Server.

c) Satu unit server database yang memiliki spesifikasi Processor Intel Pentium Core 2 Duo @ 2,93GHz, RAM 2 GB, Hard Disk 250 GB, dengan OS Linux Ubuntu Server.

\section{HASIL DAN PEMBAHASAN}

Pengujian parameter pada load balancing bertujuan untuk melihat kemampuan server dalam melayani sejumlah permintaan yang datang dari pengguna dalam satuan waktu tertentu. Dalam pengujian tersebut parameter yang diukur adalah response time dan throughput baik sebelum maupun setelah load balancing berhasil diimplementasikan. Pada rincian di atas, menunjukkan bahwa alamat IP 192.168.100.107 merupakan alamat yang dimiliki oleh load balancer yang berfungsi untuk meneruskan permintaan ke aplikasi server. Ketika pengguna meminta konten di server aplikasi, maka semua permintaan akan melewati server load balancer. Jadi pengguna tidak akan mengetahui real server mana yang melayani. Kemudian permintaan layanan tersebut akan dibagikan oleh server load balancer kepada server aplikasi yang ada di belakangnya dengan menyesuaikan pada algoritma penjadwalan yang telah disematkan. Selanjutnya setiap server aplikasi akan terhubung ke server database untuk menyesuaikan data yang akan digunakan, setelah itu permintaan akan di berikan kepada client melalui server load balancer kembali. Pengamatan dalam penelitian ini dilakukan dengan mengambil dua parameter yaitu throughput dan response time. Pengamatan ini bertujuan untuk membandingkan antara sebelum dan setelah load balancer di implementasikan. Dalam melakukan pengujian, pada sisi klien akan melakukan permintaan secara bertahap terhadap server aplikasi melalui tool httperf untuk melihat hasil dari nilai throughput dan response time. Untuk Hasil perbandingan request sebelum dan setelah penerapan load balancing dapat di lihat pada Tabel 1. Dimana permintaan layanan tersebut akan dilakukan secara bertahap. Dimulai dari jumlah koneksi 100/s, 200/s, 300/s, 400/s dan 500/s koneksi yang dilakukan secara bersamaan dalam satu waktu. Dari sini maka dapat dilakukan pengamatan serta membandikan kondisi sebelum dan setelah load balancing di implementasikan. Berdasarkan pada hasil yang telah diperoleh dari nilai throughput dan responsetime.

Tabel 1. Hasil perbandingan request sebelum dan setelah dibangunya load balancing

\begin{tabular}{|r|c|c|c|c|c|}
\hline \multirow{2}{*}{ No } & \multirow{2}{*}{$\begin{array}{c}\text { Jumlah } \\
\text { Koneksi }\end{array}$} & Respon time $(\mathrm{ms})$ & Throughput (KB/s) & Respon time (ms) & Throughput (KB/s) \\
\cline { 3 - 6 } & & 6,98 & 49,4 & 5,38 & 49,4 \\
\hline 1 & $100 / \mathrm{s}$ & 5,24 & 98,8 & 5,5 & 98,8 \\
\hline 2 & $200 / \mathrm{s}$ & 1145,4 & 121,4 & 4,99 & 148,2 \\
\hline 3 & $300 / \mathrm{s}$ & Terdapat error & Terdapat error & 4,52 & 197,6 \\
\hline 4 & $400 / \mathrm{s}$ & Terdapat error & Terdapat error & 23,55 & 246,76 \\
\hline 5 & $500 / \mathrm{s}$ & 12,64 & 231,524 & 53,92 & 8,788 \\
\hline \multicolumn{2}{|c|}{ Rata-rata Total } & \multicolumn{2}{|c|}{} \\
\hline
\end{tabular}

Hasil rata-rata waktu respon sebelum load balancing dan setelah load balancing adalah berbeda. Nilai waktu respon sebelum load balancing rata-rata lebih tinggi dibanding setelah penerapan load balancing seperti terlihat pada Gambar 3. 


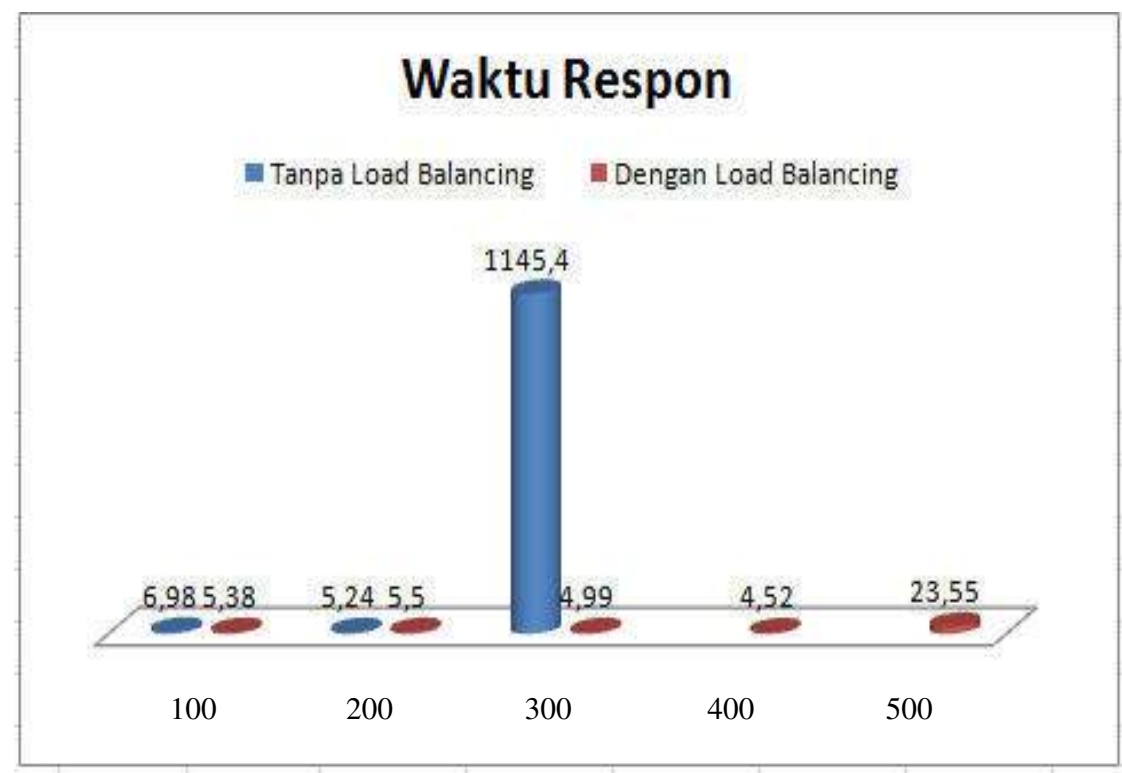

Gambar3 : Grafik Waktu Respon (ms)

Berdasarkan Gambar 3 terlihat bahwa setiap kenaikan jumlah permintaan maka diikut juga dengan naiknya nilai waktu response dimana ketika jumlah koneksi diangka 300 terlihat perbedaan nilai. Sebelum load balancing waktu respon yang tercatat mencapai 1145,4 ms sedangkan setelah load balancing waktu yang tercatat adalah hanya 4,99 ms. Untuk koneksi 400 dan 500 terjadi error ketika dilakukan pengukuran pada pada sistem tanpa load balancing sehingga nilai yang di hasilkan tidak valid. Ini dikarenakan kemampuan sistem server terbatas di angka koneksi 300.Secara keseluruhan rata-rata menunjukan bahwa setelah load balancing waktu server merespon permintaan pengguna lebih cepat dibanding sebelum load balancing. Hal ini karena setiap permintaan yang ada dibagi merata pada dua server aplikasi dibelakangnya, sehingga beban server menjadi berkurang dan kinerja server aplikasi menjadi meningkat.

Hasil pengukuran menunjukan bahwa nilai rata-rata throughput sebelum load balancing lebih rendah dibanding setelah penerapan load balancing seperti terlihat pada Gambar 4.

Gambar 4 : Grafik Throughput $(\mathrm{Kb} / \mathrm{Sec})$

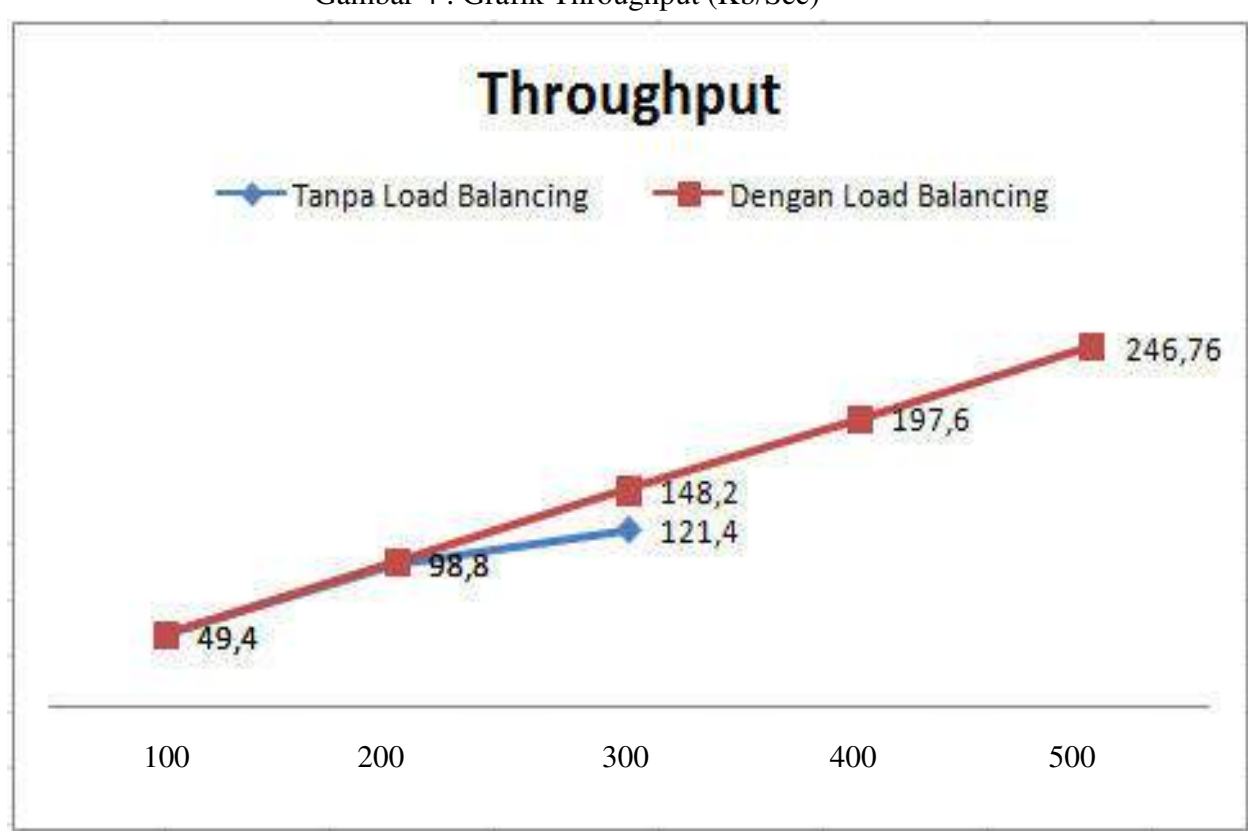


Berdasarkan Gambar 4 terlihat bahwa ketika jumlah koneksi diangka 300 terlihat perbedaan pada nilai throughput. Untuk koneksi 400 dan 500 terjadi error ketika dilakukan pengukuran pada sistem server tunggal sehingga nilai yang di hasilkan tidak valid. Ini dikarenakan kemampuan sistem server terbatas di angka koneksi 300. Besarnya paket data yang dapat ditransmisikan setelah load balancing disebabkan karena setiap paket yang masuk dapat didistribusikan secara merata pada kedua server aplikasi dibelakangnya sehingga dapat mengurangi beban yang berlebih. Nilai throughput yang besar ini menunjukan kinerja aplikasi meningkat.

\section{SIMPULAN DAN SARAN}

\section{A. Kesimpulan}

Dari penelitian yang dilakukan mengenai implementasi metode load balancing pada sistem kluster server didapatkan beberapa kesimpulan sebagai berikut:

1. Skalabilitas dari sistem server menjadi meningkat. Ini dikarenakan beban yang masuk dapat didistribusikan ke masing-masing server dengan seimbang. Sehingga tidak terjadi penumpukan beban pada salah satu server saja.

2. Penerapan metode load balancing pada sistem kluster server dapat memperkecil nilai response time serta meningkatkan nilai throughput dimana ketika permintaan diatas 300 koneksi sistem dengan load balancing masih dapat melayani permintaan dari pengguna dibandingkan tanpa load balancing dimana server hanya mampu melayani permintaan sampai dengan 300 koneksi. Ini dibuktikan ketika sistem dengan load balancing diberiakan 300 koneksi, memiliki nilai response time 4,99 ms serta throughput 148,2 KB/s dan ini lebih baik jika dibandingkan dengan sistem tanpa load balancing yang memiliki nilai response time $1145,4 \mathrm{~ms}$ dan throughput 121,4 KB/s. Sehingga dengan implementasi load balancing, maka kinerja layanan dari sistem kluster server dapat terus ditingkatkan. Artinya sistem dapat terhindar dari kelebihan beban yang datang dari pengguna.

\section{B. Saran}

Melihat dari hasil penelitian dan pengembangan yang telah dilakukan, ada beberapa saran yang mungkin dapat dikerjakan untuk peneliti selanjutnya diantaranya diperlukan penelitian lebih lanjut tentang algoritma penjadwalan yang akan digunakan dalam pendistribusian beban koneksi. Selain itu juga diperlukan penelitian lebih jauh tentang fault tolerance agar server load balancing dapat bebas dan terhindar dari kegagalan.

\section{DAFTAR PUSTAKA}

Lukitasari, D., dan Oklilas, A.F., 2010. AnalisisPerbandingan Load Balancing Web Server Tunggal Dengan Web server Cluster Menggunakan Linux Virtual Server. Jurnal Generic, Vol.5 No.2:2010. ISSN: 19074093. Fakultas Ilmu Komputer Universitas Sriwijaya.

Kopper, K., 2005. The Linux Enterprise Cluster-Build a Highly Available Cluster with Commodity Hardware and Free Software. No Starch Press, Inc. San Francisco.

W. Tarreau, “Making Applications Scalable,” no. September, pp. 1-18, 2006.

Kopparapu, C., 2002. Load Balancing Servers, Firewalls, and Caches. Wiley Computer Publishing.John Wiley \& Sons, Inc.New Y ork Chichester Weinheim Brisbane Singapore Toronto.

Rabu, J.A., Purwadi, J., dan Raharjo, W.S., 2012. Implementasi Load Balancing Menggunakan Web Server Metode LVS-NAT. Jurnal INFORMATIKA Vol. 8, No. 2.

U. Haluoleo, K. Bumi, and T. Anduonohu, "Peningkatan Kinerja Siakad Menggunakan Metode Load Balancing dan Fault Tolerance Di Jaringan Kampus Universitas Halu Oleo,” vol. 10, no. 1, pp. 11-22, 2016.

Chang, H.S., Chang, Y.M., dan Hsiao, S.Y., 2014. Scalable Network File Systems with Load Balancing and Fault Tolerance for Web Services. The Journal of Systems and Software. 93.102-109. Elsevier. 
E. Mit, N. H. Borhan, and M. A. Khairuddin, "Need analysis of culture-based genealogy software for indigenous communities,” 2012 IEEE Symp. E-Learning, E-Management E-Services, IS3e 2012, pp. $61-65,2012$. 